\title{
Global Assessment of Power Quality Performance of Networks using the Analytic Hierarchy Process Model
}

\author{
Document Version \\ Accepted author manuscript
}

Link to publication record in Manchester Research Explorer

\section{Citation for published version (APA):}

Abdelrahman, S., Liao, H., Guo, T., Guo, Y., \& Milanovic, J. (2015). Global Assessment of Power Quality Performance of Networks using the Analytic Hierarchy Process Model.

\section{Citing this paper}

Please note that where the full-text provided on Manchester Research Explorer is the Author Accepted Manuscript or Proof version this may differ from the final Published version. If citing, it is advised that you check and use the publisher's definitive version.

\section{General rights}

Copyright and moral rights for the publications made accessible in the Research Explorer are retained by the authors and/or other copyright owners and it is a condition of accessing publications that users recognise and abide by the legal requirements associated with these rights.

\section{Takedown policy}

If you believe that this document breaches copyright please refer to the University of Manchester's Takedown Procedures [http://man.ac.uk/04Y6Bo] or contact uml.scholarlycommunications@manchester.ac.uk providing relevant details, so we can investigate your claim.

\section{OPEN ACCESS}




\title{
Global Assessment of Power Quality Performance of Networks using the Analytic Hierarchy Process Model
}

\author{
Sami Abdelrahman, Graduate Student Member, IEEE, Huilian Liao, Member, IEEE, Tingyan Guo, Graduate Student \\ Member, IEEE, Yue Guo and Jovica V. Milanović, Fellow, IEEE, \\ School of Electrical and Electronic Engineering \\ The University of Manchester \\ Manchester, UK \\ milanovic@manchester.ac.uk
}

\begin{abstract}
Power Quality is one of the critical issues when operating contemporary distribution networks. The increased interest in PQ is due to the increased employment of sensitive equipment loads and renewable generation technologies. Currently, the evaluation of PQ network performance is based on evaluating different phenomena separately, and a standardised way to evaluate the $P Q$ as a whole for a bus or a network is yet to be applied or widely accepted. The paper presents a methodology for combining the performances of different $P Q$ phenomena and expressing the $P Q$ performance of a bus using a single index. The proposed methodology adopts an Analytic Hierarchy Process (AHP) model to combine the harmonics, unbalance and voltage sag performances in one proposed index; i.e. Compound Bus PQ Index (CBPQI). The separate and cumulative $P Q$ performances of a 295-bus generic distribution network were evaluated, compared and demonstrated using heat maps.
\end{abstract}

Index Terms-AHP, global index, Monte Carlo, power quality

\section{INTRODUCTION}

Power Quality (PQ) has regained interest from Distribution Network Operators (DNOs) in recent years mainly due to the increased employment of more efficient, but also more PQ sensitive, load equipment and the increase in connection of renewable power electronics interfaced distributed generation (DG). Phenomena like harmonics, voltage fluctuations and unbalance are particularly affected by the increased penetration of intermittent stochastic DG units. While fulfilling the main aim of PQ regulation, as stated in Council of European Energy Regulators (CEER) report [1], namely, to ensure that the customers' equipment is not affected by the PQ disturbances, DNOs are also trying to minimise their operation costs. They begin to consider internal (planning) limits for their PQ performance to satisfy sensitive customers' needs, or, minimally, try to operate below the standard compatibility PQ levels where most of the customers will be immune to disturbances. This led to ideas such as differentiated PQ provision and premium PQ contracts being more attractive for both customers and utilities, especially in today's deregulated competitive electricity markets [2]. These concerns about PQ performances has led to increased deployment of PQ monitors [3], which in turn has led to an abundance of PQ data being collected from all over the network. These data must be synthesised and analysed properly to yield useful information about PQ performance levels for both DNOs and customers.

The current practice of PQ evaluation of a bus or a network is to evaluate the relevant phenomena separately. A number of PQ objectives and indices are adopted for evaluating the PQ performance [4]. All of the common PQ phenomena are suitably described separately in the international and national standards, with an exception of voltage transients. Issues like measurement techniques, compatibility and planning levels as well as acceptable levels of emissions are described and agreed upon. For example, the IEC 61000-4-30 and IEEE P1159 describe the general PQ measurements and monitoring methods and practice. Other standards describe specific phenomenon like in IEC 61000-36 and IEEE 519 where the harmonics phenomenon is well defined and described. The main problem, still not well defined, is how to perform comprehensive PQ evaluation. If an area of the network was performing well below the harmonics limits while at the same time a high number of sags and transients were recorded in the area, is it good or bad area in terms of overall PQ performance? If some mitigating measures are to be employed in these areas with variable PQ performance with respect to different phenomena, what would be the optimal mitigation solution?

Some past papers and reports tried to combine different PQ phenomena in a single index. The earliest reported work [5] compared the recorded voltage sine-wave to the ideal expected sine-wave, and assessed the performance of several PQ phenomena like sag, harmonics and transients. References $[6,7]$ proposed a framework for compressing the recorded PQ measurements of different phenomena into one index by normalising and numerically consolidating the different PQ phenomena indices. References [8-10] adopted the cost of PQ disturbances in the overall evaluation of PQ, by adopting an Analytic Hierarchy Process (AHP) model. In [11] the concept of $P Q$ reserve, i.e. the 'distance' between the PQ performance levels and the predefined thresholds, for evaluating PQ performance of the buses was introduced. The minimum reserve or the sum of exceeding PQ phenomena (negative

This work was supported by SuSTAINABLE Project under Grant 308755. 


\section{$>$ ACCEPTED VERSION OF THE PAPER <}

reserves) was adopted as the evaluating index. Fuzzy based global PQ indices were proposed in [12-15]. The efficiency of the fuzzy system in modelling the uncertainties was utilised in PQ global evaluation when considering different levels of the importance (weights) of different PQ phenomena. Despite all these efforts for unified presentation of $P Q$, a standardised way of overall PQ evaluation is yet to be widely agreed upon. It is inevitable to lose some information while presenting different phenomena in a single index; however, depending on the application, the global assessment of PQ using one index can be proved useful and adequate. Applications like identification of poor PQ performing areas, comparison between buses and optimisation of PQ solutions are suggested in this paper.

This paper presents a methodology for combining the performance of different PQ phenomena into a single, global PQ index. The harmonics, unbalance and voltage sag are chosen as an illustrative example to illustrate the methodology. The methodology adopts an Analytic Hierarchy Process (AHP) mathematical model for combining the separate performances. The different phenomena are initially separately evaluated based on simulations and then, their individual "performance" is combined into single index using appropriate weighting factors based on the requirements of different loads or their importance to the utility. A Compound Bus PQ Index CBPQI is proposed and used to identify the weak areas in the network in terms of PQ. Comparisons are performed between the separate and combined PQ evaluations using heat maps to validate the accuracy and representation of the index.

\section{ANALYTIC HIERARCHY PROCESS}

The Analytic Hierarchy Process (AHP) is a mathematical model for solving multi criteria decision making problems. Fig. 1 shows the block diagram of an example of AHP model for solving a problem of hiring a new manager. As shown in the figure, the selection criteria are the qualifications, personal skills and experience. Each criterion will have a pre-defined weight on the final selection. The alternatives Candidate 1, $2, \ldots, n$ will have different scores in each selected criterion, then based on the weighting of the different criteria the total score for each candidate will be calculated. The candidate with the highest score can be selected as the final goal. More details about the mathematical models can be found in [16].

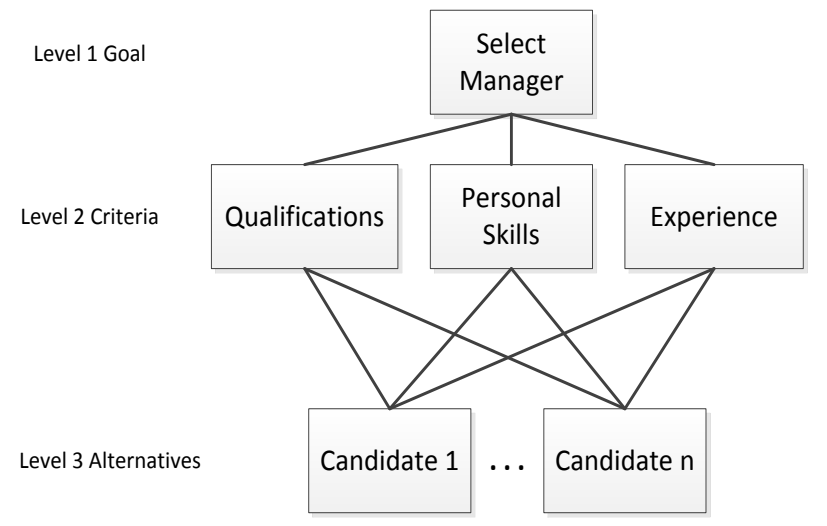

\section{MethodolOGY}

The methodology proposed for the comprehensive PQ evaluation of a bus can be divided into three main steps. First, collect the measurements (or simulation results) at the buses under study, analyse the data statistically and calculate the adopted index (e.g. the $95^{\text {th }}$ percentile of voltage total harmonic distortion THD for harmonics evaluation). Second, evaluate the PQ phenomena separately by comparing the performances to appropriate limits (from standards or PQ contracts) and determine the weighting of each phenomenon based on the sensitive load types at the bus, or the cost of disturbances. Finally, apply the AHP model to calculate CBPQI $_{\mathrm{i}}$ combining the performances of the considered phenomena at $\mathrm{Bus}_{\mathrm{i}}$, and evaluate the overall network performance by ranking buses based on global PQ performance. Fig. 2 shows the general framework of the proposed methodology.

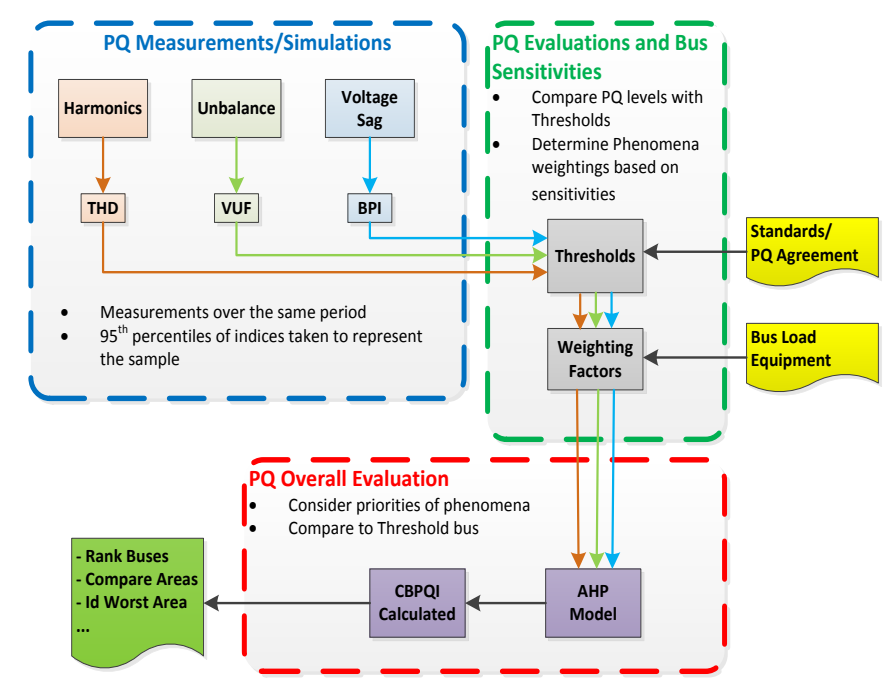

Fig. 2. Framework for overall PQ evaluation

\section{A. Test Network}

The proposed methodology is applied on a generic distribution network. The test network used to illustrate the proposed approach is the 295 bus Generic Distribution Network (GDN), Fig. 3. The network parameters are based on realistic UK distribution network parameters [17, 18]. The network consists of 295 buses, 276 branches (overhead lines and cables), and 37 transformers with various winding connections. The network comprises five $400 \mathrm{kV}$ buses, and four $275 \mathrm{kV}$ buses (transmission level connection points) a sub-transmission level of twenty-three $132 \mathrm{kV}$ buses and twenty-five $33 \mathrm{kV}$ buses, and a distribution level of 233 buses of $11 \mathrm{kV}$ level and four $0.4 \mathrm{kV}$ buses. A detailed description and parameters of the network can be found on [19]. Three types of loads (domestic, commercial and industrial) and three types of Distributed Generation (fuel cell, photovoltaic and DFIG based wind turbine) are modelled in the network, with maximum penetration of DGs not exceeding $30 \%$ of the load at the feeder throughout the year. The evaluation was 


\section{$>$ ACCEPTED VERSION OF THE PAPER <}

performed for the $11 \mathrm{kV}$ level only (231 bus, blue shaded area in Fig. 3).

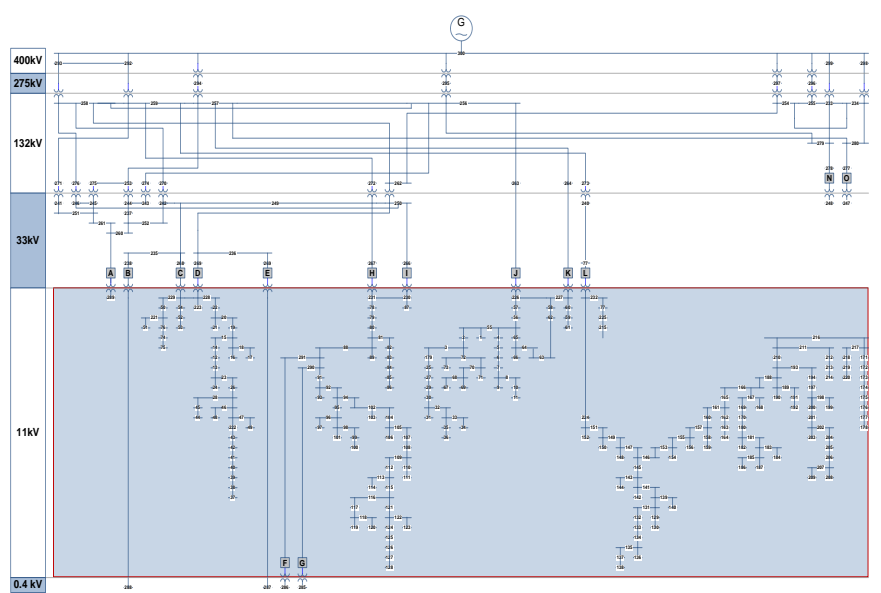

Fig. 3: Test network single line diagram

\section{B. $P Q$ Simulations}

The methodology is demonstrated using probabilistic simulation results generated in DIgSILENT/PowerFactory software package for the considered PQ phenomena. The uncertainties involved in the PQ simulations are handled using Monte Carlo simulations. Uncertainties like injections of harmonic currents, load unbalance levels and load sensitivity to different sag events are considered. The simulation results collected for each phenomenon for all the buses and the $95^{\text {th }}$ percentiles are then taken as the performance measures. The simulations for the continuoustype phenomena (harmonics and unbalance) where performed at different operating points while the annual performance of the event-type phenomenon (voltage sag) is adopted in all the studies.

\section{1) Voltage Sag}

The simulation of voltage sag performance of a bus is performed by considering all network component faults that might lead to sag events at the considered bus. The severity of each sag event, i.e. probability of causing a trip, is calculated based on probabilistic SEMI F47 curves [20], Fig 4. The sag bus performance index $\mathrm{BPI}^{\mathrm{S}}$ is then calculated based on the severity of each sag event and the expected frequency of the fault causing the event. Further details are presented in [21, 22].

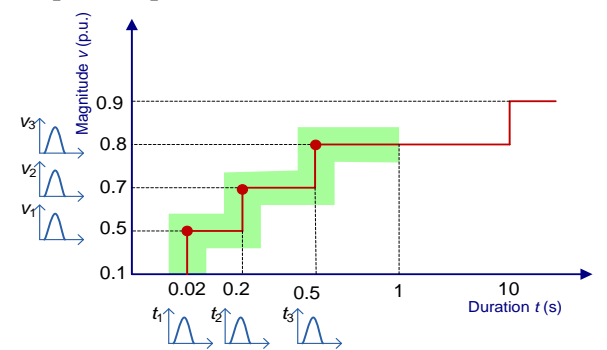

Fig. 4. Probabilistic SEMI F47 voltage tolerance curves (adopted from [21])

\section{2) Harmonics}

The harmonic simulations are performed by selecting a number of different types of non-linear loads in addition to the DG units as sources of harmonic current injections. The injections' currents are sampled from normally distributed ranges with average values adopted from the literature for different types of loads and DGs. Fig 5 shows injection range examples of 1.5 A load. Monte Carlo harmonic load flow is performed at different operating points and the $95^{\text {th }}$ percentile THD, for every bus, is taken as the evaluating index. Further details of harmonic evaluation can be found in [23, 24].

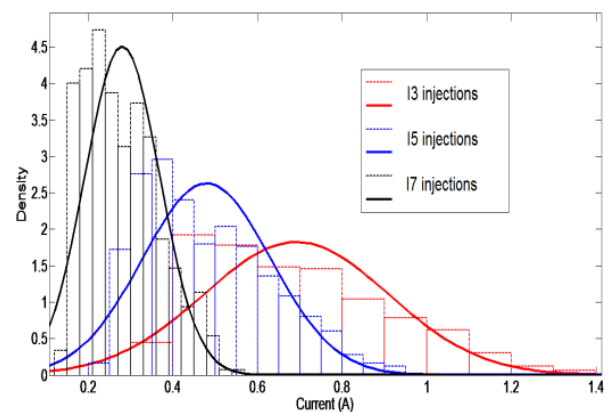

Fig. 5. Harmonic current injections samples

3) Voltage Unbalance

The voltage unbalance sources in the network are the single phase connected DG units, in addition to a number of selected loads. The load levels of unbalance are simulated by randomly sampling the power factor values for each phase from normally distributed ranges (Fig. 6), simulating different levels of reactive power injections from each phase at the selected unbalance sources. Further details of unbalance simulation are presented in [25].
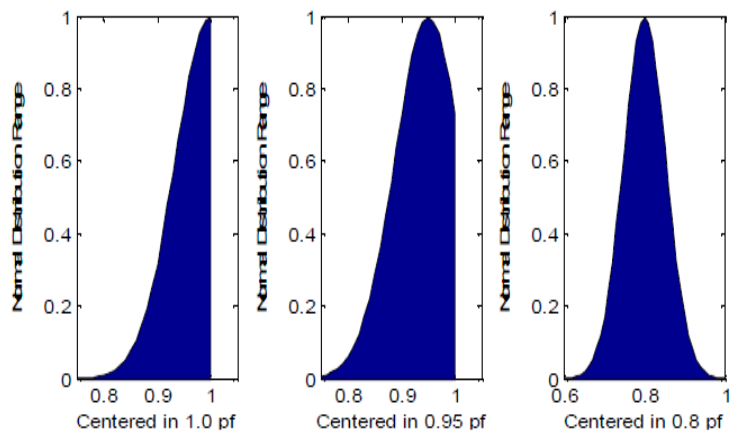

Fig. 6. Unbalance sources power factor ranges (adopted from [25])

\section{Separate Evaluations and Bus Sensitivities}

The thresholds for the harmonics and voltage unbalance phenomena are adopted from the standards $(\mathrm{THD}=5 \%$ and $\mathrm{VUF}=2 \%$ ), and for the voltage sag index a value of BPI $=3$ p.u. was selected for all the buses under evaluation. However, the methodology is flexible and can consider tighter or more relaxed thresholds for different buses, as evaluation may be necessary at some buses where PQ contracts are adopted. The weighting factors can be based on the ratio of certain load types to the total load at the bus, e.g. where at a certain bus the dominant load type is three phase motors, the unbalance can be assigned higher weights than the other phenomena. Another method for adopting weighting factors can be based on the impact of the PQ disturbance, e.g., the phenomenon with higher disturbance costs can be assigned higher weights. 


\section{Overall $P Q$ Evaluation using $C B P Q I$}

By applying the AHP model and considering different priorities for different phenomena, the $\mathrm{CBPQI}_{\mathrm{i}}$ can be calculated for all the buses. The AHP model (shown in Fig. 1) was modified for the purpose of the proposed methodology. At Level 3 Alternatives, the comparison is performed between two alternatives, the bus under study Bus ${ }_{i}$ and the thresholds bus Bus ${ }_{\mathrm{Th}}$ (a bus where all considered phenomena are at their limits). The scores of the two alternatives in each considered phenomenon are weighted by the corresponding weight of the phenomenon (Level 2 Criteria). Then the total score of the bus under study $\mathrm{Bus}_{\mathrm{i}}$ is compared to the thresholds bus Bus $\mathrm{Th}_{\mathrm{T}}$ to evaluate its performance and calculate the global performance index CBPQI $\mathrm{I}_{\mathrm{i}}$. The weighting factors were selected assuming the voltage sag is the most important phenomenon $\left(w_{\text {sag }}=15\right)$, the harmonics phenomenon has moderate importance $\left(w_{\text {har }}=10\right)$ and the voltage unbalance is assumed to be the least important in this evaluation $\left(w_{u n b}=8\right)$. At the alternatives level, the comparison between $\mathrm{Bus}_{\mathrm{i}}$ and Bus $_{\mathrm{TH}}$ was performed using the pair-wise comparison matrix, taking the principle eigenvector as the 'score'. Similarly, to assign 'priority' for each phenomenon the pair-wise matrix and the eigenvector are used [16]. Table I (a) and (b) show the comparison matrix for calculating the scores for the buses based on the harmonic performance (Alternatives Level) and the comparison matrix for calculating the priorities of the considered phenomena based on the assigned weights (Criteria Level), respectively.

Table I: Pair-wise comparison matrix

(a) Alternatives comparison

\begin{tabular}{|c|c|c|c|}
\hline Harmonics & Bus $_{\mathrm{i}}$ & Bus $_{\mathrm{Th}}$ & Eigenvector \\
\hline Bus $_{\mathrm{i}}$ & 1 & $\mathrm{THD}_{\mathrm{Th}} / \mathrm{THD}_{\mathrm{i}}$ & Score $_{\mathrm{i}}$ \\
\hline Bus $_{\mathrm{Th}}$ & $\mathrm{THD}_{\mathrm{i}} / \mathrm{THD}_{\mathrm{Th}}$ & 1 & Score $_{\mathrm{Th}}$ \\
\hline
\end{tabular}

(b) Priorities comparison

\begin{tabular}{|c|c|c|c|c|}
\cline { 2 - 5 } \multicolumn{1}{c|}{} & Sag & Harmonics & Unbalance & $\begin{array}{c}\text { Priorities } \\
\text { (Eigenvector) }\end{array}$ \\
\hline Sag & 1 & $w_{\text {sag }} / w_{\text {har }}$ & $w_{\text {sag }} / w_{\text {unb }}$ & $p_{\text {sag }}$ \\
\hline Harmonics & $w_{\text {har }} / w_{\text {sag }}$ & 1 & $w_{\text {har }} / w_{\text {unb }}$ & $p_{\text {har }}$ \\
\hline Unbalance & $w_{\text {unb }} / w_{\text {sag }}$ & $w_{\text {unb }} / w_{\text {har }}$ & 1 & $p_{\text {unb }}$ \\
\hline
\end{tabular}

The total weighted score of Bus is then calculated by summing up the multiplications of the scores of the bus in each criterion (PQ phenomenon) by the priority of the phenomenon. The $\mathrm{CBPQI}_{\mathrm{i}}$ is calculated by comparing the total score of Bus $\mathrm{B}_{\mathrm{i}}$ to the total score of $\mathrm{Bus}_{\mathrm{Th}}$, as shown in (1) where $N$ is the total number of considered phenomena,

$$
C B P Q I_{i}=\frac{\sum_{n=1}^{N} \text { score }_{i, n} \times p_{n}}{\sum_{n=1}^{N} \text { score }_{T h, n} \times p_{n}} .
$$

\section{RESULTS AND ANALYSIS}

To demonstrate the results of the PQ simulations, heat maps were produced. Fig. 7 shows the results for the operating hour with the maximum DG penetration in the year. The separate phenomena evaluating indices $\left(\mathrm{BPI}^{\mathrm{S}}\right.$, THD and VUF) are shown in Fig. 7 (a), (b) and (c) respectively, and the results of the global assessment (CBPQI) are shown in Fig. 7 (d). The overall performance for another, randomly chosen, operating point is shown in Fig. 8. At that point, the worst

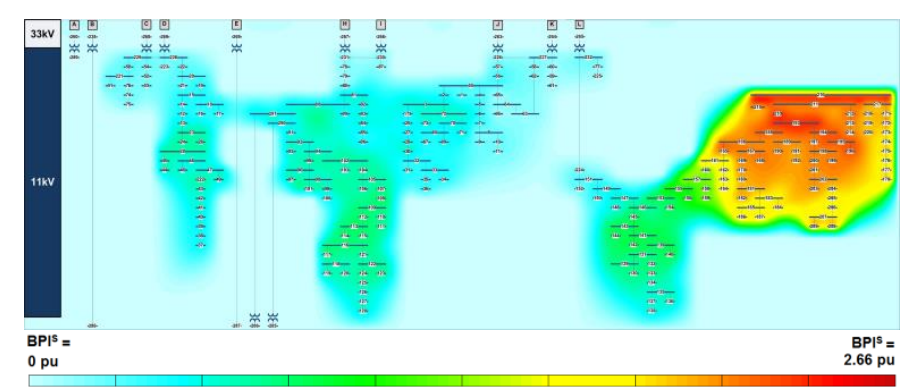

(a) Voltage sag performance

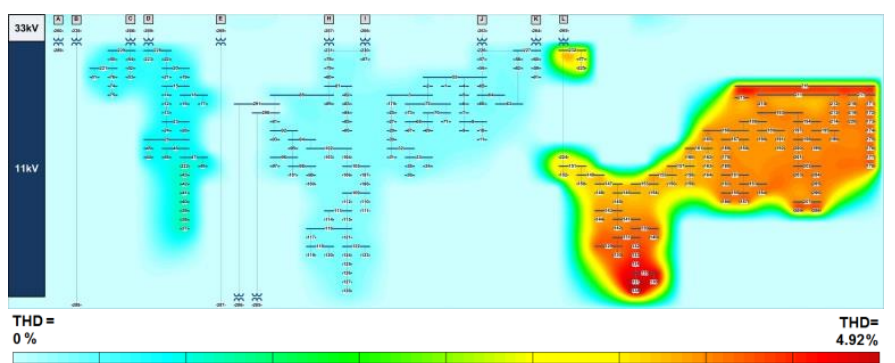

(b) Harmonics performance

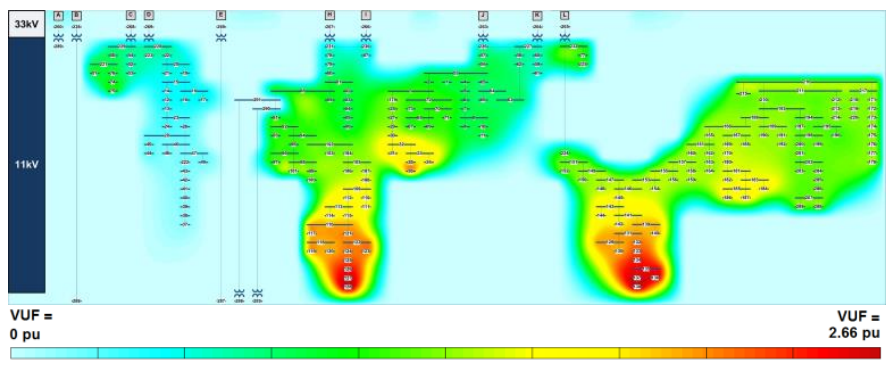

(c) Voltage Unbalance performance

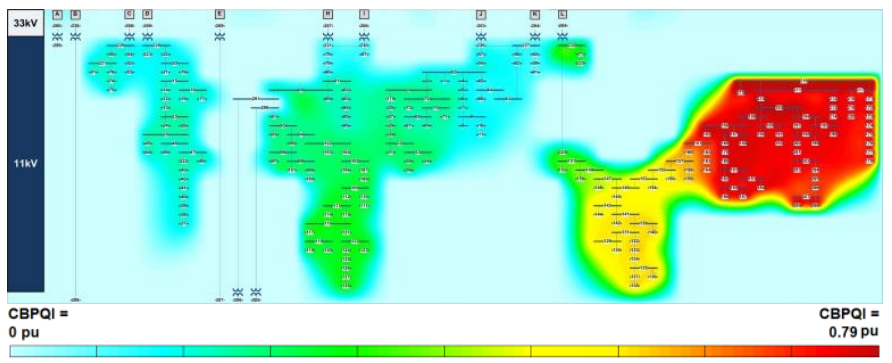

(d) Overall Performance

Fig. 7. Individual and overall PQ performances (maximum DG penetration)

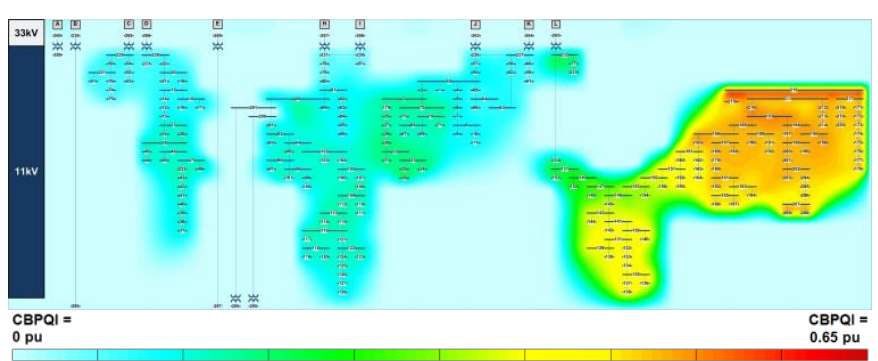

Fig. 8. Overall PQ performance for randomly selected operating point

performing buses for each phenomenon separately resulted in $\mathrm{BPI}^{\mathrm{S}}=2.6, \mathrm{THD}=4.1 \%$ and $\mathrm{VUF}=2.1 \%$.

By inspecting Fig. 7 it can be seen that the CBPQI follows the trend of the voltage sag phenomenon (high importance phenomenon based on assigned weights), i.e., the areas where the voltage sag is relatively poorly performing when combined 


\section{$>$ ACCEPTED VERSION OF THE PAPER <}

with critically performing areas in terms of harmonics (moderate importance) and unbalance (low importance), yield the overall critical PQ performance in the same area. Similarly, The areas where poor performances were recorded for the harmonics and unbalance (moderate and low importance), but good performance in terms of voltage sag, were found to be moderately performing in terms of the overall PQ performance (the bottom right hand side yellow area in the overall map in Fig. 7 (d)).

In order to look closer into the buses performance, Fig. 9 and Table II were produced. The five worst buses in each PQ phenomenon (shaded gray in Table II) are normalised based on the maximum recorded values, then plotted along with the corresponding calculated CBPQI. Buses 136, 137 and 138 were among the worst performing buses in terms of both, harmonics and unbalance; therefore only 12 buses are shown in Fig. 9. Again, the influence of the weightings on the global assessment can be noted here. The CBPQI (striped bars) exceed 0.7 p.u. when the sag index (black bars) is high or when both, harmonics (dark grey bars) and unbalance performances (light grey bars) are poor (high values of normalized performance). The impact of poor performance in unbalance only was masked (hidden) in a way, with good performances in both sag and harmonics, as shown in case of buses 127 and 128, which both recording less than 0.4 p.u. CBPQI values despite having high VUF values.

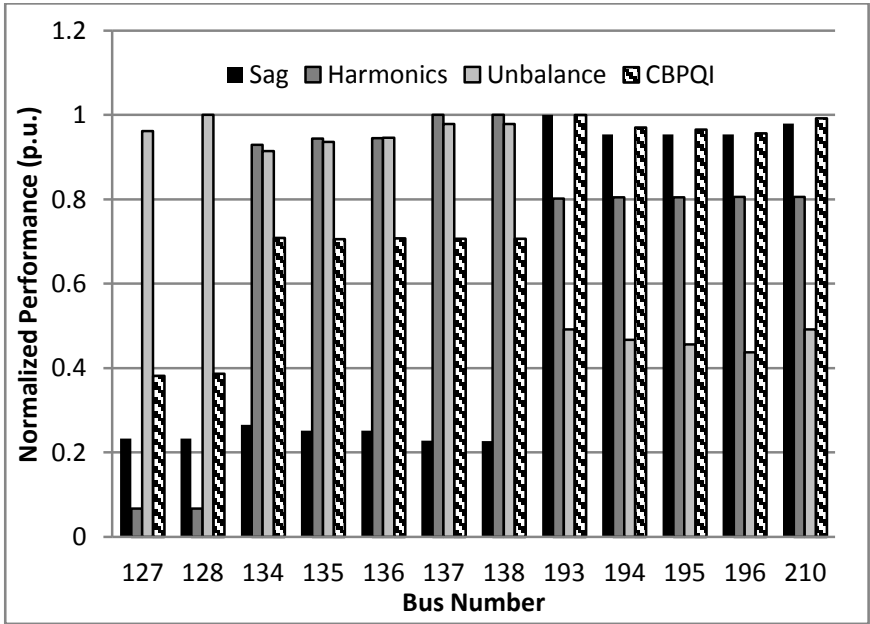

Fig. 9. Worst performing buses in the separate evaluation

Table II: Worst performing buses in all considered phenomenon

\begin{tabular}{|c|c|c|c|c|c|c|c|c|}
\hline $\begin{array}{l}\text { ש্ } \\
\vdots \\
\#\end{array}$ & 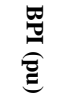 & $\underset{*}{\widetilde{Z}}$ & فㅂ & $\vec{\exists}$ & 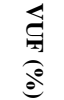 & 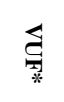 & 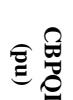 & $\underset{*}{\underline{0}}$ \\
\hline 127 & 0.62 & 0.23 & 0.33 & 0.07 & 2.50 & 0.96 & 0.30 & 0.38 \\
\hline 128 & 0.62 & 0.23 & 0.33 & 0.07 & 2.60 & 1.00 & 0.31 & 0.39 \\
\hline 134 & 0.71 & 0.27 & 4.57 & 0.93 & 2.38 & 0.91 & 0.56 & 0.71 \\
\hline 135 & 0.67 & 0.25 & 4.64 & 0.94 & 2.44 & 0.94 & 0.56 & 0.71 \\
\hline 136 & 0.67 & 0.25 & 4.65 & 0.95 & 2.46 & 0.95 & 0.56 & 0.71 \\
\hline 137 & 0.61 & 0.23 & 4.92 & 1.00 & 2.55 & 0.98 & 0.56 & 0.71 \\
\hline 138 & 0.61 & 0.23 & 4.92 & 1.00 & 2.55 & 0.98 & 0.56 & 0.71 \\
\hline 193 & 2.67 & 1.00 & 3.94 & 0.80 & 1.28 & 0.49 & 0.79 & 1.00 \\
\hline 194 & 2.54 & 0.95 & 3.95 & 0.80 & 1.22 & 0.47 & 0.77 & 0.97 \\
\hline 195 & 2.54 & 0.95 & 3.96 & 0.80 & 1.19 & 0.46 & 0.76 & 0.97 \\
\hline 196 & 2.54 & 0.95 & 3.96 & 0.81 & 1.14 & 0.44 & 0.76 & 0.96 \\
\hline 210 & 2.61 & 0.98 & 3.96 & 0.81 & 1.28 & 0.49 & 0.78 & 0.99 \\
\hline
\end{tabular}

*normalised based on maximum value
The presented illustrative results show that CBPQI can be used to identify the worst performing areas of the network and rank the buses in terms of overall PQ performance. Furthermore, the CBPQI can be used as an objective function in optimization problems for developing PQ mitigation solution. The multi-objective optimisation problem can be significantly simplified by transferring the problem into single objective optimisation. Fig. 10 shows preliminary results of constrained optimisation problem to develop PQ mitigation solution across the network. A range of PQ mitigation solution devices (for the three considered phenomena) were utilised to minimise the CBPQI across the network considering different threshold levels for CBPQI in different areas of the network. It can be seen that the overall PQ performance in the network can be significantly improved and brought below the specified thresholds in different areas by focusing on minimizing single performance index.

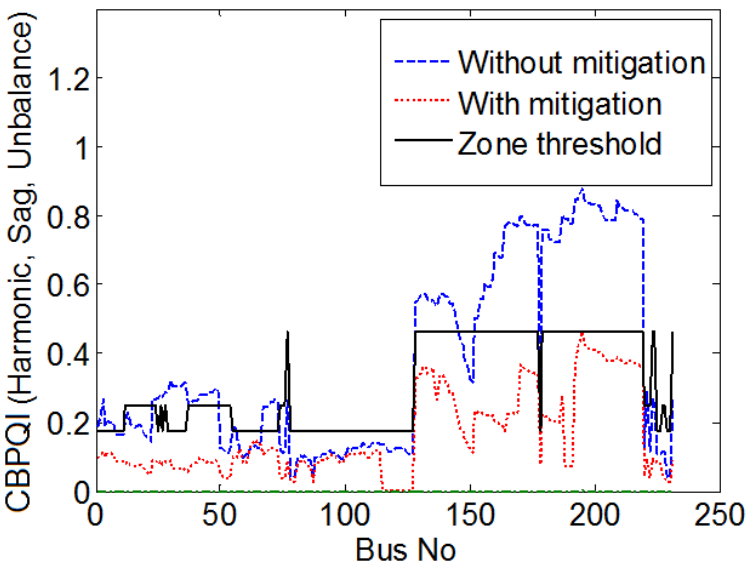

Fig. 10. Buses overall $P Q$ performance with/without mitigation solutions

\section{CONCLUSION}

The paper introduces a new index, Compound Bus PQ Index CBPQI, for global evaluation of PQ performance of network buses. The index based on AHP model considers a number of phenomena simultaneously, (voltage sag, harmonics, and voltage unbalance in this illustrative example) by applying appropriate, user specified, thresholds and weights for each phenomenon. The index can be used to simplify identification of poorly performing areas of the network in terms of global PQ performance, for PQ benchmarking of buses and areas of the network and to simplify development of optimal PQ mitigation solutions for the network.

\section{REFERENCES}

[1] Council of European Energy Regulators, "5th CEER Benchmarking Report on The Quality of Electricity Supply," CEER 2011.

[2] E.L.M. Smeets W.T.J. Hulshorst, J.A. Wolse, "Premium Power Quality contracts and labeling," KEMA 2007.

[3] JWG Cigre/Cired C4.112, "GUIDELINES FOR POWER QUALITY MONITORING," Cigre 2014.

[4] JWG Cigre C4.07/Cired, "POWER QUALITY INDICES AND OBJECTIVES," Cigre 2004.

[5] N. R. Watson, C. K. Ying, and C. P. Arnold, "A global power quality index for aperiodic waveforms," in Proc. 2000 Harmonics and Quality of Power Ninth Int. Conf., vol. 3, pp. 1029-1034 vol.3. 


\section{$>$ ACCEPTED VERSION OF THE PAPER <}

[6] V. J. Gosbell, B. S. P. Perera, and H. M. S. C. Herath, "Unified power quality index (UPQI) for continuous disturbances," in Proc. 2002 Harmonics and Quality of Power, 10th Int. Conf., vol. 1, pp. 316-321 vol.1.

[7] V.J. Gosbbell. B.S.P. Perera and H.M.S.C. Herath, "New Framework for Utility Power Quality (PQ) Data Analysis," in Proc. 2001 AUPEC'01, pp. 577-582.

[8] Lee Buhm and Kim Kyoung Min, "Unified power quality index based on value-based methodology," in Proc. 2009 IEEE PES Power \& Energy Society General Meeting, pp. 1-8.

[9] Lee Buhm and Kim Kyoung Min, "Development of ideal analytic hierarchy process -application of power quality," in Proc. 2009 FUZZIEEE Fuzzy Systems Int. Conf., pp. 64-67.

[10] Lee Buhm, Kim Kyoung Min, and Goh Yeongjin, "Unified power quality index using ideal AHP," in Proc. 2008 Harmonics and Quality of Power 13th Int. Conf., pp. 1-5.

[11] Jan Meyer, Peter Schegner, Gert Winkler, Michael Muhlwitz, Drewag Stadtwerke, and Lutz Schulze, "Efficient method for power quality surveying in distribution networks," in Proc. 2005 Electricity Distribution, CIRED 18th Int. Conf. and Exhib., pp. 1-4.

[12] S. A. Farghal, M. S. Kandil, and A. Elmitwally, "Quantifying electric power quality via fuzzy modelling and analytic hierarchy processing," in IEE Proc.2002 Generation, Transmission and Distribution, , vol. 149 , no. 1, pp. 44-49.

[13] W. Morsi and M. El-Hawary, "Fuzzy-wavelet-based electric power quality assessment of distribution systems under stationary and nonstationary disturbances," in Proc. 2010 IEEE Power and Energy Society General Meeting, pp. 1-1.

[14] A. Salarvand, B. Mirzaeian, and M. Moallem, "Obtaining a quantitative index for power quality evaluation in competitive electricity market," Generation, Transmission \& Distribution, IET, vol. 4, no. 7, pp. 810-823, 2010.

[15] G. A. Vokas, S. D. Kaminaris, P. A. Kontaxis, M. Rangoussi, G. C. Ioannidis, S. A. Papathanassiou, P. V. Malatestas, and F. V. Topalis, "Electric network power quality assessment using fuzzy expert system methodology," in Proc. 2012 Power Generation, Transmission, Distribution and Energy Conversion (MEDPOWER), 8th Mediterranean Conf., pp. 1-6.
[16] Luis G. Vargas Thomas L. Saaty, Models, Methods, Concepts \& Applications of the Analytic Hierarchy Process. New York: Springer Science and Business Media, 2012

[17] S. Bahadoorsingh, J. V. Milanovic, Zhang Yan, C. P. Gupta, and J. Dragovic, "Minimization of Voltage Sag Costs by Optimal Reconfiguration of Distribution Network Using Genetic Algorithms," IEEE Trans. on Power Delivery, vol. 22, no. 4, pp. 2271-2278, 2007.

[18] Milanovic, x, J. V., and Lu Jingwei, "Application Of artificial immune system for detecting overloaded lines and voltage collapse prone buses in distribution network," in Proc. 2009 IEEE PowerTech, pp. 1-7.

[19] Yan Zhang, "Techno-economic Assessment of Voltage Sag Performance and Mitigation," $\mathrm{PhD}$, University of Manchester, Manchester, 2008

[20] Equipment Voltage Sag Immunity Spec. Semicon. Process, SEMIF47-0706. Available: www.semi.org. [Online].

[21] H. Liao, S. Abdelrahman, Y. Guo, and J. V. Milanovic, "Identification of Weak Areas of Power Network Based on Exposure to Voltage Sags -Part I: Development of Sag Severity Index for Single-Event Characterization," accepted for publication in the IEEE Trans. Power Del., DOI: 10.1109/TPWRD.2014.2362965.

[22] H. Liao, S. Abdelrahman, Y. Guo, and J. V. Milanovic, "Identification of Weak Areas of Network Based on Exposure to Voltage Sags -Part II: Assessment of Network Performance Using Sag Severity Index," accepted for publication in the IEEE Trans. Power Del., DOI: 10.1109/TPWRD.2014.2362957.

[23] Abdelrahman S., Liao H., Yu J., and and Milanovic J. V., "Probabilistic Assessment of the Impact of Distributed Generation and Non-linear Load on Harmonic Propagation in Power Networks," in Proc. 2014Power Systems Computation Conference (PSCC), vol., no., pp.1,7.

[24] Abdelrahman S., Liao H., and and Milanovic J. V., "The Effect of Temporal and Spatial Variation of Harmonic Sources on Annual Harmonic Performance of Distribution Networks " in Proc. 2014 IEEE PES Innovative Smart Grid Technologies Conference Europe (ISGT-Europe), vol., no., pp.1,6.

[25] Liu Zhixuan and J. V. Milanovic, "Probabilistic estimation of propagation of unbalance in Distribution Network with asymmetrical loads," in Proc. 2012 Power Generation, Transmission, Distribution and Energy Conversion (MEDPOWER), 8th Mediterranean Conf., pp. 1-6. 